\title{
Correspondence
}

\section{Sexist language}

Sir: New Zealand has, this year, been celebrating the Centenary of Women's Suffrage. Even prior to this auspicious occasion the Royal Australian and New Zealand College of Psychiatrists has amended all references to 'manpower' issues to 'workforce' issues. I note in the Psychiatric Bulletin, 1993, 17, a reference to a College Manpower Census. I would respectfully like to suggest that the Royal College of Psychiatrists considers following the lead of its antipodean colleagues in using appropriately non-sexist language.

Joanna MacDonald, Hutt Valley Health Corporation Ltd, Hillview, 32 Pretoria Street, Lower Hutt, New Zealand

Sir: I welcomed Dr MacDonald raising 'a rose by any other name'.

As the first female President of this College, I am a member of the Standing Medical Manpower Advisory Committee to our female Secretary of State for Health and an ex-Chairman of the College's Manpower Committee. We are in an era of change and the first report of the former body, published last year, is entitled Planning the Medical Workforce.

I am sure that the appropriate committees of the Royal College of Psychiatrists will consider changing the names of the Manpower Committee and the College's manpower census if the membership expresses the view that we should do so. I should be grateful if members would write to me accordingly.

On a personal note I should like to to quote from Jane Austen's Sense and Sensibility:

"Eleanor agreed with it all, for it did not seem worth the compliment of rational opposition".

Fiona CaldicotT, President, The Royal College of Psychiatrists

\section{Possible changes to the MRCPsych Part II examination}

Sir: Having recently undergone the 'trauma' of sitting the MRCPsych Part II examination, I wondered if other psychiatric trainees would agree with some of the ways in which I feel the exam could be changed and hopefully improved.
First, it might be useful to consider making it such that candidates may not attempt the clinical/oral exam unless they have first passed the written papers. I understand that this is currently the case for the Part II MRCP exam, which is paid for by two separate cheques - one to cover the fee for the written exam, and the other to cover the fee for the clinical. A candidate who is not successful in the written papers then has the cheque for the clinical part returned to him.

It seems to me that this would have the following benefits:

(a) Candidates are spared having to go through the clinical when their previous performance in the written papers means that they are not likely to pass the examination anyway.

(b) It would reduce the financial burden that trainees have to bear, as exam fees are not refundable by employers.

(c) It would reduce the number of clinicals that the College would need to organise, with fewer patients and examiners being needed.

(d) If all the candidates doing the clinicals knew they had already passed the written exam, it might lead to increased determination to put up a better performance in the clinical exam.

(e) Successful candidates could probably be informed much sooner, if not straightaway, of their success. This would avoid the long waiting period candidates are currently having to endure.

I would be interested to read the views of other candidates and the College examiners on this issue.

AKINTUNDE AKINKUNMI, Napsbury Hospital, London Colney, St Albans AL2 IAA

Sir: As members of the College will be aware, the examination is constantly reviewed by the Monitoring Panel of the Examination Sub-Committee. We will be interested to read comments and correspondence that flows from this letter, particularly as it is likely that a more extensive review of the examination will be undertaken within the next two years.

Sheila Mann, Chief Examiner, The Royal College of Psychiatrists 